\title{
Correction: Postvaccination Fever Response Rates in Children Derived Using the Fever Coach Mobile App: A Retrospective Observational Study
}

Sang Hyun Ahn ${ }^{1 *}$, MD; Jooho Zhiang ${ }^{2 *}$, BS; Hyery Kim³ ${ }^{3}$ MD, PhD; Seyun Chang ${ }^{4}$, BS; Jaewon Shin ${ }^{4}$, MD; Myeongchan Kim ${ }^{4}, \mathrm{MD}$; Yura Lee ${ }^{5}, \mathrm{MD}, \mathrm{PhD}$; Jae-Ho Lee ${ }^{5,6}$, MD, PhD; Yu Rang Park ${ }^{7}, \mathrm{PhD}$

\footnotetext{
${ }_{1}^{1}$ Korea Human Resource Development Institute for Health and Welfare, Cheongju, Republic of Korea

${ }^{2}$ Yonsei University College of Medicine, Seoul, Republic of Korea

${ }^{3}$ Department of Pediatrics, University of Ulsan College of Medicine, Asan Medical Center Children's Hospital, Seoul, Republic of Korea

${ }^{4}$ Mobile Doctor Co, Ltd, Seoul, Republic of Korea

${ }^{5}$ Department of Biomedical Informatics, Asan Medical Center, Seoul, Republic of Korea

${ }^{6}$ Department of Emergency Medicine, Asan Medical Center, University of Ulsan College of Medicine, Seoul, Republic of Korea

${ }^{7}$ Department of Biomedical Systems Informatics, Yonsei University College of Medicine, Seoul, Republic of Korea

*these authors contributed equally
}

\section{Corresponding Author:}

Yu Rang Park, PhD

Department of Biomedical Systems Informatics

Yonsei University College of Medicine

50-1 Yonsei-ro, Seodaemun-gu

Seoul, 03722

Republic of Korea

Phone: 8222282493

Email: yurangpark@yuhs.ac

\section{Related Article:}

Correction of: https://mhealth.jmir.org/2019/4/e12223/

(JMIR Mhealth Uhealth 2020;8(5):e18921) doi: 10.2196/18921

The authors of "Postvaccination Fever Response Rates in Children Derived Using the Fever Coach Mobile App: A Retrospective Observational Study" (JMIR Mhealth Uhealth 2019;7(4):e12223) identified an error in the Acknowledgements section.

In the first part of the Acknowledgements section, the following phrase:

This work was supported by Technology Innovation Program (10060085) funded by the Ministry of Trade, Industry, and Energy (MOTIE, KOREA)
Has been changed to:

This work was supported by Technology Innovation Program (20002289) funded by the Ministry of Trade, Industry, and Energy (MOTIE, KOREA)

The correction will appear in the online version of the paper on the JMIR website on May 7, together with the publication of this correction notice. Because this was made after submission to PubMed, PubMed Central, and other full-text repositories, the corrected article has also been resubmitted to those repositories.

This is a non-peer-reviewed article. Submitted 27.03.20; accepted 01.04.20; published 07.05.20.

Please cite as:

Ahn SH, Zhiang J, Kim H, Chang S, Shin J, Kim M, Lee Y, Lee JH, Park YR

Correction: Postvaccination Fever Response Rates in Children Derived Using the Fever Coach Mobile App: A Retrospective Observational Study

JMIR Mhealth Uhealth 2020;8(5):e18921

URL: https://mhealth.jmir.org/2020/5/e18921

doi: $10.2196 / 18921$

PMID: 32379698 
(C) Sang Hyun Ahn, Jooho Zhiang, Hyery Kim, Seyun Chang, Jaewon Shin, Myeongchan Kim, Yura Lee, Jae-Ho Lee, Yu Rang Park. Originally published in JMIR mHealth and uHealth (http://mhealth.jmir.org), 07.05.2020. This is an open-access article distributed under the terms of the Creative Commons Attribution License (https://creativecommons.org/licenses/by/4.0/), which permits unrestricted use, distribution, and reproduction in any medium, provided the original work, first published in JMIR mHealth and uHealth, is properly cited. The complete bibliographic information, a link to the original publication on http://mhealth.jmir.org/, as well as this copyright and license information must be included. 